\title{
FIGO Stage IIIA Ovarian Cancer
}

National Cancer Institute

\section{Source}

National Cancer Institute. FIGO Stage IIIA Ovarian Cancer. NCI Thesaurus. Code

C128087.

Ovarian cancer with positive retroperitoneal lymph nodes and/or microscopic metastasis beyond the pelvis. (FIGO, 2014) 